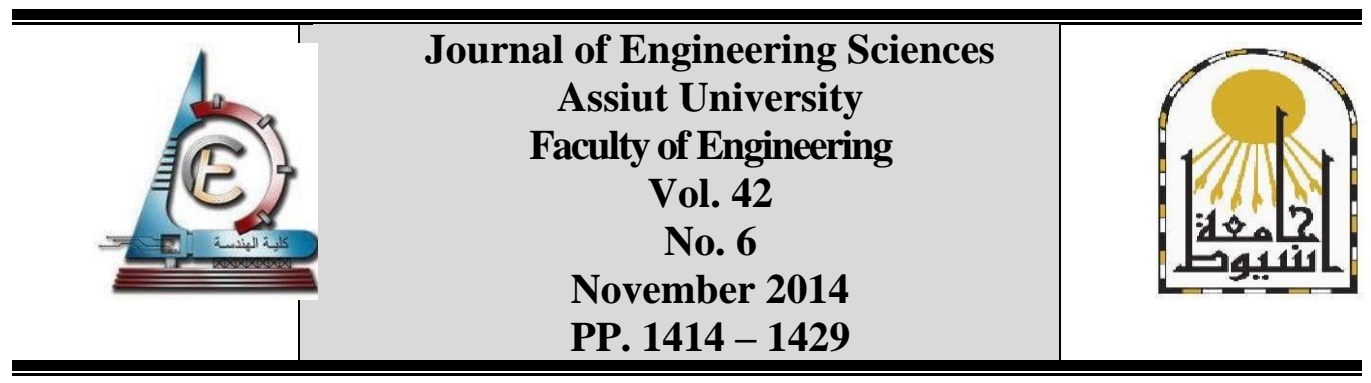

\title{
PERFORMANCE STUDY OF A MODIFIED RANQUE-HILSCH VORTEX TUBE
}

\author{
Mohamed S. El-Soghiar *, Mohamed F. F. El-Dosoky, \\ Ali K. Abdel-Rahman, Hany A. Mohamed, Mahmoud G. Morsy \\ Department of Mechanical Eng, Faculty of Engineering, Assiut University, Assiut71516, Egypt.
}

(Received 1 November 2014; Accepted 15 December 2014)

\begin{abstract}
In the present work, a Ranque-Hilsch vortex tube (RHVT) is modified by suggesting a novel vortex chamber at inlet. The performance of the modified vortex tube is studied experimentally. Suggested lengths for the vortex chamber are 10,15, and $20 \mathrm{~mm}$ and the vortex chamber diameters are 12, 16, and $20 \mathrm{~mm}$. All vortex chambers with different lengths and diameters are tested experimentally at variable inlet conditions. It's found that the vortex chamber diameter has a dominant effect on the performance compared with the vortex chamber length. The results are compared with that obtained by a conventional vortex tube. The results show that the vortex chamber gives an enhancement in the isentropic efficiency reach to $15.9 \%$. The results for a vortex chamber of $15 \mathrm{~mm}$ length and 20 $\mathrm{mm}$ diameter has the best performance.
\end{abstract}

Keywords: vortex tube, vortex chamber.

\section{Introduction}

Vortex tube is a simple device, which splits the pressurized gas stream into two low pressure streams (cold and hot streams). Vortex tube has different names as Ranque vortex tube (first discoverer), and Hilsch vortex tube or Ranque-Hilsch, RHVT, who improved vortex tubes performance after Ranque. Vortex tube is composed from inlet nozzles (1), vortex chamber (2), cold orifice (3), hot tube (4), hot control valve (hot plug) (5), and hot exit (6), as shown in figure 1.

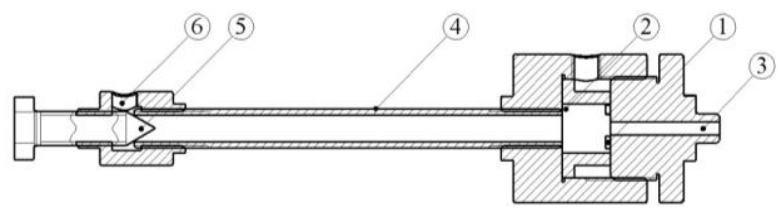

Fig. 1. Vortex tube components.

* Corresponding author.

Email address: mohamedel_soghier@yahoo.com 
In a counter-flow RHVT, compressed gas tangentially enters the nozzles to produce a highly vortex flow. The gas flows toward the hot plug at which an amount of the hot gas escaped from the peripheral of the tube. The remained gas returns back to the cold orifice along the center of the cold exit, as shown in figure 2. In a uni-flow RHVT, the cold and hot streams of gas exit from the central orifice and peripheral of the tube, at one end of the tube, as in figure 3. Generally, the performance of the counter-flow RHVT would be better than that of the uni-flow RHVT.

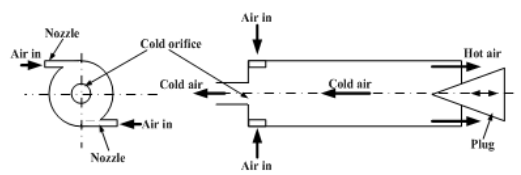

Fig. 2. Counter-flow RHVT.

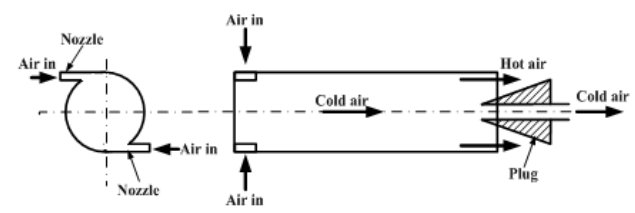

Fig. 3. Uni-flow RHVT.

The RHVT has many advantages, such as no refrigerant, compact, low maintenance, no moving parts, simple, low cost, lightweight, and instant cold and hot gas. Thus, the vortex tube can be used in many applications as cooling, heating, drying, gas liquidfication, separation of mixture, cooling of machinery during operation, cooling electrical devices, and cooling vest. The only disincentive in the uses of the vortex tube is its small cooling capacity.

Experimental studies are focused on enhancement the performance of the vortex tubes. Different geometrical vortex tubes are tested with different thermo-physical parameters [13]. The aims of the theoretical studies are to obtain the velocity, temperature, and pressure distributions of the flow structure inside the RHVT. The flow pattern is obtained by using a commercial CFD packages.

Wu et al. [4] design a new nozzle to enhance the efficiency of the vortex tube. Dincer et al. [5] studied the effect of position, diameter, and angle of a mobile plug located at the hot outlet side. Aydin et al. [6] developed a new geometry of vortex generator at the cold end side. Markal et al. [7] investigated the effects of the hot valve angle. Xue and Arjomandi [8] examined the effect of vortex angle on the vortex tube performance. Valipour and Niazi [9] studied the influence of uniform curvature of main tube. Eiamsa-ard et al. [10] examined the effect of cooling a hot tube side. Eiamsa-ard [11] investigated the vortex tube with multiple inlet snail enteries. Nimbalkar and Muller [12] studied the effect of the cold orifice diameter. Chang et al. [13] examined the effect of the divergent in the hot tube side. Gao et al. [14] used a special pitot tube and thermocouple techniques to measure the pressure, velocity and temperature distribution inside a counter flow vortex tube with Nitrogen. Xue et al. [15] and Aydin and Baki [3] studied the flow structure by the flow visualization.

In this paper, an experimental study is carried out to study the effect of vortex chamber geometry on the energy separation and on the vortex tube efficiency at different operating conditions. 


\section{Experimental setup}

The schematic diagram of the test rig used in the experimental works is shown in figure 4. The compressor (1) supply the air through the dryer (2) and the filter (3) to trap the moisture content from the air flow. Air tank (4) is used to insure continuously air flow to the test rig. Air flow is controlled by valve (5) and its pressure is regulated by the pressure regulator (6). Air pressure and temperature are measured at the inlet and the exit by digital pressure manometers and thermocouples, respectively. Air flow rates at the cold and hot exit are measured by digital flow meters (7). A conical plug (8) at the hot exit is used to change the flow rate exit from the periphery of the hot exit. The thermocouples are located $50 \mathrm{~mm}$ before inlet and $60 \mathrm{~mm}$ after exit ends. The measuring instruments characterization and uncertainty are given in table 1 .

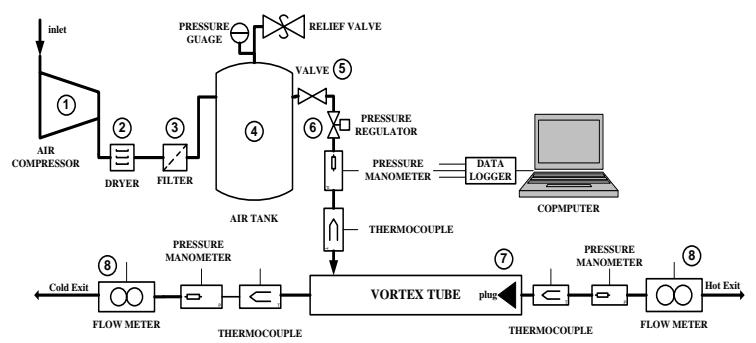

Fig. 4. The schematic diagram of the experimental setup.

Table 1.

Measuring instruments characterization and its uncertainty.

\begin{tabular}{|l|l|l|}
\hline Instrument & Range & Uncertainty \\
\hline Thermocouple type (T) & -185 to $400{ }^{\circ} \mathrm{C}$ & $\pm 0.5^{\circ} \mathrm{C}$ \\
\hline Digital pressure manometer & $0-50 \mathrm{bar}$ & $\pm 10 \mathrm{mbar}$ \\
\hline Volumetric flow meter & $0-500 \mathrm{SLPM}$ & $\pm 0.1 \mathrm{SLPM}$ \\
\hline Pressure regulator model C70 & $0-20 \mathrm{bar}$ & - \\
\hline
\end{tabular}

Conventional vortex tube (conventional inlet nozzles) and modified vortex tube (modified vortex chamber) are manufactured for the present work. The conventional vortex tube with its dimensions is shown in figure 5. The vortex tube with modified vortex chamber and its dimensions is shown in figure 6. Schematic diagram of the conventional inlet nozzles and modified vortex chamber are shown in figures 7 and 8, respectively.

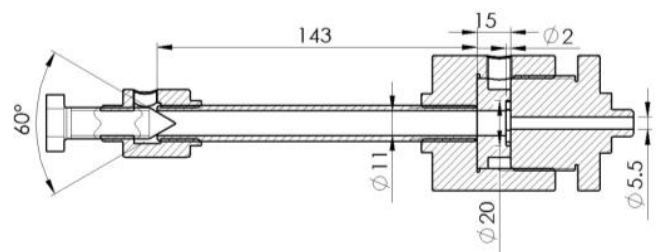

Fig. 5. Conventional vortex tube.

The tested vortex tube specifications are given in table 2 . Various vortex chambers with different diameters and lengths are tested at inlet pressures range of 0.5 to 3 bar. The outer surface of the vortex chamber, cold and hot exits, and hot tube are insulated. 


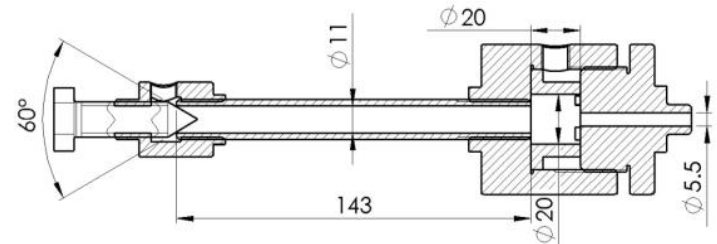

Fig. 6. Vortex tube with modified vortex chamber.
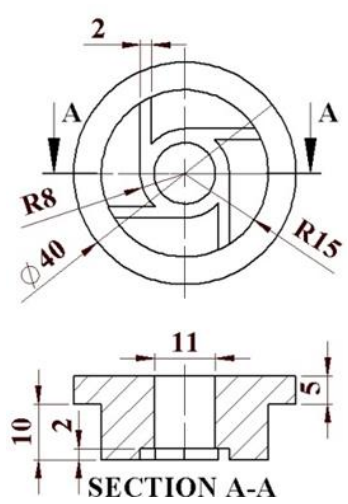

Fig. 7. Conventional inlet nozzles.
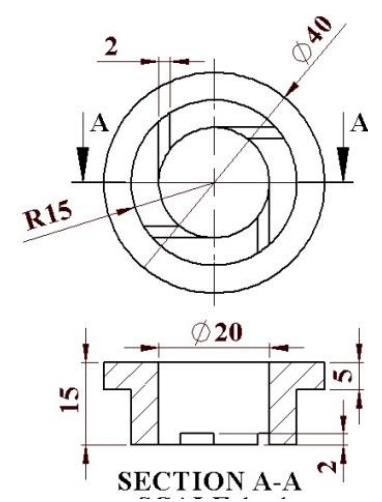

Fig. 8. Modified vortex chamber.

Table 2.

Tested vortex tube specifications.

\begin{tabular}{|l|l|l|}
\hline Component & Dimension & material \\
\hline Inlet nozzle & (No. off 4), $2 \times 2 \mathrm{mms}$ & brass \\
\hline Hot tube & diameter $=11 \mathrm{~mm}$ and length $=143 \mathrm{~mm}$ & steel \\
\hline Cold orifice & $5.5 \mathrm{~mm}$ & steel \\
\hline Hot plug & $60^{\circ}$ & steel \\
\hline Modified vortex chamber & $\mathrm{D}=12,16,20 \mathrm{mms}$, and $\mathrm{L}=10,15,20 \mathrm{mms}$. & brass \\
\hline
\end{tabular}

\section{Analysis}

Vortex tube performance evaluated by the following terms:

The cold mass fraction is defined as: 


$$
m_{c f}=\frac{\dot{m}_{c}}{\dot{m}_{i}}
$$

Where $\dot{\mathrm{m}}_{\mathrm{c}}$ is the cold air mass flow rate in $\mathrm{kg} / \mathrm{s}, \dot{\mathrm{m}}_{\mathrm{i}}$ is the inlet mass flow rate in $\mathrm{kg} / \mathrm{s}$.

The hot mass fraction is defined as:

$$
m_{h f}=\frac{\dot{m}_{h}}{\dot{m}_{i}}
$$

Where $\dot{m}_{h}$ is the hot air mass flow rate in $\mathrm{kg} / \mathrm{s}$.

The cold temperature difference is obtained from Eq. (3).

$$
\Delta T_{c}=T_{i}-T_{c}
$$

Where $T_{i}$ is the inlet air temperature in $k$ and $T_{c}$ is the cold air temperature in ${ }^{\circ} k$.

The hot temperature difference is given by

$$
\Delta T_{h}=T_{h}-T_{i}
$$

Where $T_{h}$ is the hot air temperature in ${ }^{\circ} \mathrm{k}$.

Coaling efficiency, defined as the cooling load divided by total inlet energy, is expressed by Eq. (5).

$$
\eta_{c}=\frac{m_{c f}\left(T_{c}-T_{i}\right)}{T_{i}}
$$

Heating efficiency, defined as the heating load divided by total inlet energy, is given by

$$
\eta_{h}=\frac{m_{h f}\left(T_{h}-T_{i}\right)}{T_{i}}
$$

The isentropic temperature difference is expressed by Eq. (7)

$$
\Delta T_{i s}=T_{i}\left(1-\left(\frac{p_{a}}{p_{i}}\right)^{\frac{\gamma-1}{\gamma}}\right)
$$

Where, $p_{a}$ is the atmospheric pressure in $k P a, p_{i}$ is the inlet air pressure in $k P a$ and $\gamma$ is the specific heat ratio.

The isentropic efficiency is calculated from Eq. (8).

$$
\eta_{i s}=\frac{\Delta T_{c}}{\Delta T_{i s}}=\frac{T_{i}-T_{c}}{T_{i}\left(1-\left(\frac{p_{a}}{p_{i}}\right)^{\frac{\gamma-1}{\gamma}}\right)}
$$




\section{Results and discussions}

\subsection{Effect of the Geometrical Parameters on the Vortex Tube Performance}

4.1.1. Effect of vortex chamber length on cold and hot temperature differences, cold and hot heating capacity and isentropic efficiency

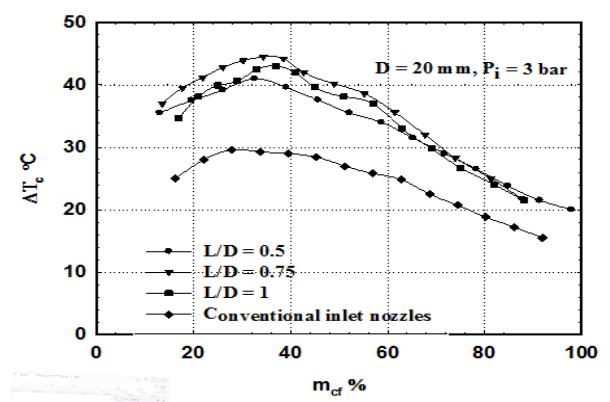

Fig. 9. Cold temperature differences $\Delta \mathrm{T}_{\mathrm{c}}$ as a function of cold mass fraction $\mathrm{m}_{\mathrm{cf}}$, for different values of $L / D$ at $P_{i}=3$ bar for $D=20 \mathrm{~mm}$.

Figures 9 and 10 show the temperature differences for cold and hot streams as a function of cold mass fraction $\mathrm{m}_{\mathrm{c}}$, at inlet pressure $\mathrm{P}_{\mathrm{i}}$ of 3 bar, and lengths of vortex chamber compared with conventional inlet nozzles at $\mathrm{D}=20 \mathrm{~mm}$. For all cases cold temperature difference increases by increasing $\mathrm{m}_{\mathrm{cf}}$ in the vicinity of $35 \%$ then decreases by increasing $\mathrm{m}_{\mathrm{cf}}$ due to the mixing of cold and hot streams. The Figs indicate that the vortex chamber length enhances the vortex tube performance. This enhancement would be due to the energy loss along the vortex chamber lengths. The performance increases by the length increase up to $15 \mathrm{~mm}$, and then the performance decays. This decay may be due to increase the effect of the peripheral friction that worsens the energy separation.

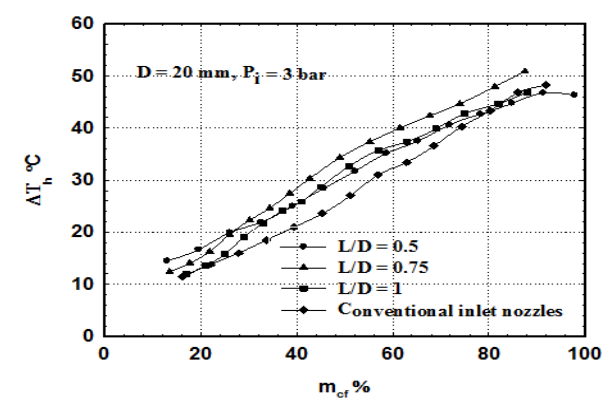

Fig. 10. Hot temperature differences $\Delta \mathrm{T}_{\mathrm{h}}$ as a function of cold mass fraction $\mathrm{m}_{\mathrm{cf}}$, for different values of $L / D$ at $P_{i}=3$ bar for $D=20 \mathrm{~mm}$.

Figures 11 and 12 show the non-dimensional cooling and heating loads, respectively, as a function of cold mass fraction $\mathrm{m}_{\mathrm{cf}}$, at inlet pressure of $3 \mathrm{bar}$, and lengths of vortex chamber compared with conventional inlet nozzles at $\mathrm{D}=20 \mathrm{~mm}$. It is demonstrated from figures 11 and 12 that vortex chamber improve $\eta_{\mathrm{c}}$ and $\eta_{\mathrm{h}}$ than the conventional vortex tube, but the improvement in $\eta_{\mathrm{c}}$ is larger than the improvement in $\eta_{\mathrm{h}}$ by $9.3 \%$. The vortex chamber of $15 \mathrm{~mm}$ Length exhibits the highest $\eta_{\mathrm{c}}$ and $\eta_{\mathrm{h}}$. 


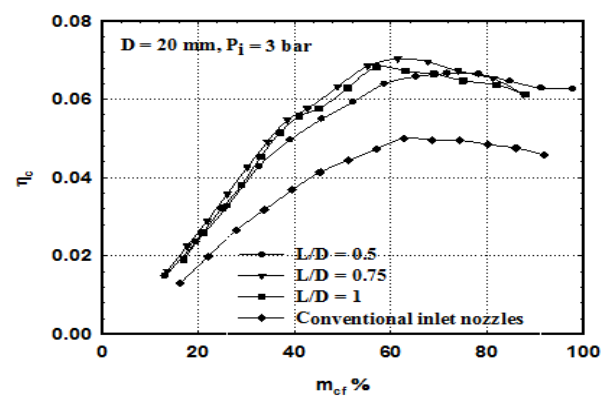

Fig. 11. Cooling efficiency $\eta_{c}$ as a function of cold mass fraction $m_{c f}$, for different values of $L / D$ at $P_{i}=3$ bar for $D=20 \mathrm{~mm}$.

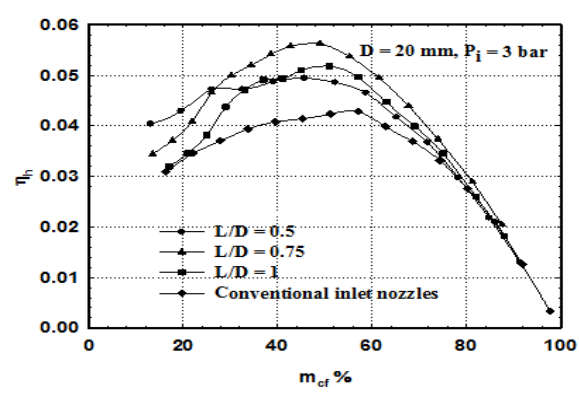

Fig. 12. Heating efficiency $\eta_{\mathrm{h}}$ as a function of cold mass fraction $\mathrm{m}_{\mathrm{cf}}$, for different values of $L / D$ at $P_{i}=3$ bar for $D=20 \mathrm{~mm}$.

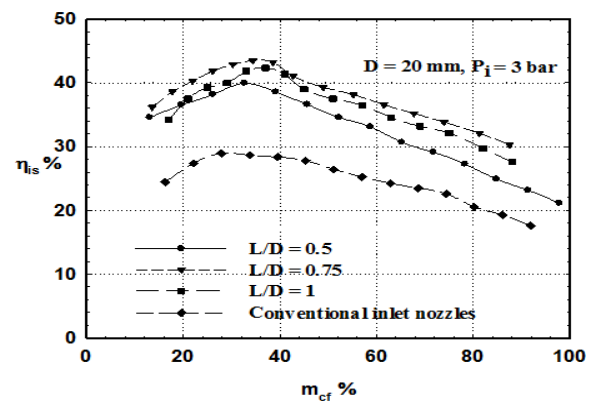

Fig. 13. Isentropic efficiency $\eta_{\text {is }}$ as a function of cold mass fraction $m_{c f}$, for different values of $L$ at $P_{i}=3$ bar for $D=20 \mathrm{~mm}$.

Figure 13 show the effect of the vortex chamber lengths and conventional inlet nozzles on the isentropic efficiency $\eta_{\text {is }}$ for $\mathrm{D}=20 \mathrm{~mm}$ at 3 bar inlet pressure. From figure 13, it can be seen that curves of $\mathrm{L} / \mathrm{D}=0.5,0.75$, and 1 are fairly closed to each other, and curve of conventional inlet nozzles is located under them. 
4.1.2. Effect of vortex chamber diameter on cold and hot temperature differences, cold and hot heating capacity and isentropic efficiency

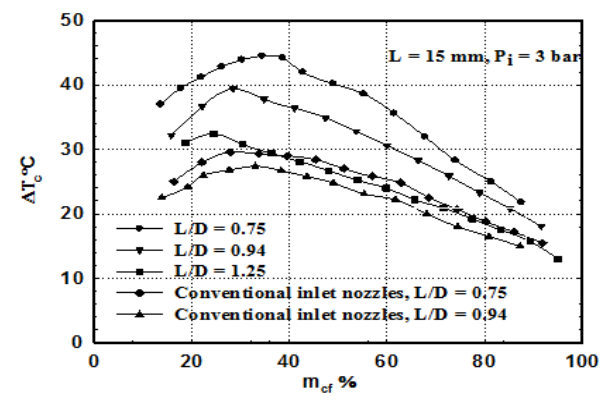

Fig. 14. Cold temperature differences $\Delta \mathrm{T}_{\mathrm{c}}$ as a function of cold mass fraction $\mathrm{m}_{\mathrm{cf}}$, for different values of $\mathrm{L} / \mathrm{D}$ at $\mathrm{P}_{\mathrm{i}}=3$ bar for $\mathrm{L}=15 \mathrm{~mm}$.

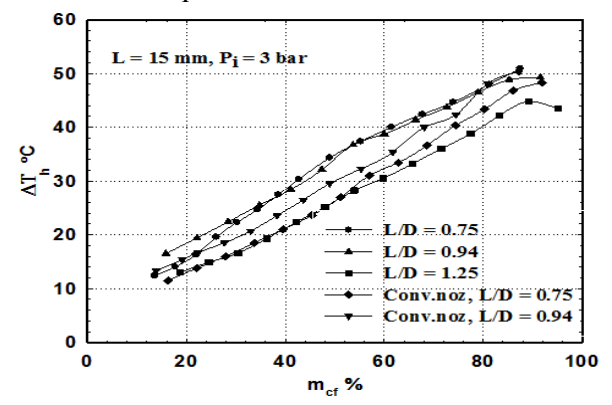

Fig. 15. Hot temperature differences $\Delta \mathrm{T}_{\mathrm{h}}$ as a function of cold mass fraction $\mathrm{m}_{\mathrm{cf}}$, for different values of $L / D$ at $P_{i}=3$ bar for $L=15 \mathrm{~mm}$.

Figures 14 and 15 show the temperature differences as a function of $\mathrm{m}_{\mathrm{cf}}$, at inlet pressure of 3 bar, and different diameters of vortex chamber compared with conventional inlet nozzles at $\mathrm{L}$ of $15 \mathrm{~mm}$. The Figs show that the effect of vortex chamber diameter in cooling is better than in heating.

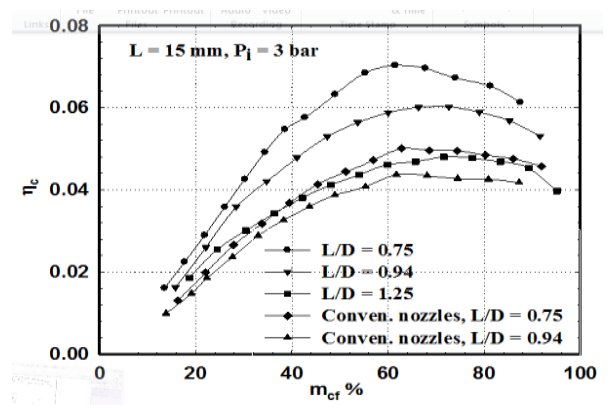

Fig. 16. Cooling efficiency $\eta_{\mathrm{c}}$ as a function of cold mass fraction $\mathrm{m}_{\mathrm{cf}}$, for different values of $L / D$ at $P_{i}=3$ bar for $L=15 \mathrm{~mm}$. 


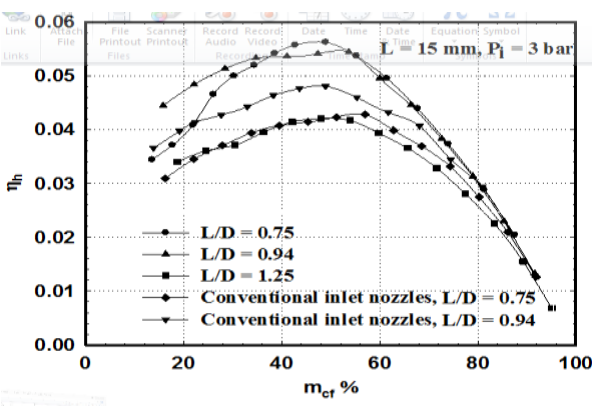

Fig. 17. Heating efficiency $\eta_{\mathrm{h}}$ as a function of cold mass fraction $\mathrm{m}_{\mathrm{cf}}$, for different values of $L / D$ at $P_{i}=3$ bar for $L=15 \mathrm{~mm}$.

Figures 16 and 17 show the non-dimensional cooling and heating loads, respectively, as a function of $\mathrm{m}_{\mathrm{cf}}$, at inlet pressure of $3 \mathrm{bar}$, and different diameters of vortex chamber compared with conventional inlet nozzles at $\mathrm{L}$ of $15 \mathrm{~mm}$. figures 16 and 17 show that vortex chamber with $\mathrm{L} / \mathrm{D}$ of 0.5 and 0.94 gave cooling efficiency higher than conventional nozzles.

From figures 11 and 12 and figures 16 and 17, it is seen that the effect of chamber diameter is more pronounced than the effect of chamber length. Vortex chamber of $20 \mathrm{~mm}$ diameter and $15 \mathrm{~mm}$ length gives the best performance for cooling and heating efficiency.

From figures 11 and $16, \eta_{\mathrm{c}}$ increases by increasing the cold mass fraction up to $60 \%$ then decreases with any increase in cold mass fraction. The rate of increase of $\eta_{\mathrm{c}}$ up to $40 \%$ cold mass fraction is higher than that rate of increasing in $\eta_{\mathrm{c}}$ between $40 \%$ and $60 \%$ cold mass fraction, and the higher rate can be contributed to the increase in $\Delta \mathrm{T}_{\mathrm{c}}$ and $\mathrm{m}_{\mathrm{cf}}$. After $60 \%$ cold mass fraction, the effect of decreasing in $\Delta \mathrm{T}_{\mathrm{c}}$ overcomes the effect of increasing $\mathrm{m}_{\mathrm{c}}$.

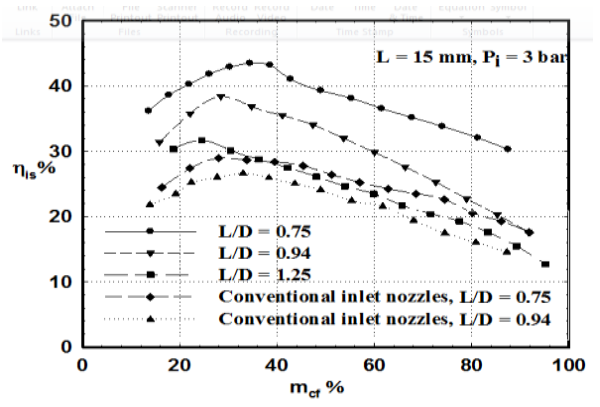

Fig. 18. Isentropic efficiency $\eta_{\text {is }}$ as a function of cold mass fraction $m_{c f}$, for different values of $L / D$ at $P_{i}=3$ bar for $L=20 \mathrm{~mm}$.

Figure 18 show the effect of the vortex chamber diameters and conventional inlet nozzles on $\eta_{\text {is }}$ for $L=15 \mathrm{~mm}$ at $\mathrm{P}_{\mathrm{i}}=3$ bar. From figure 18 it can be seen that curves of conventional inlet nozzles and D with $12 \mathrm{~mm}$ are fairly closed to each other, and curves of $\mathrm{L} / \mathrm{D}=0.94$, and 0.5 is located above them. The worse effect for $\mathrm{L} / \mathrm{D}=1.25$ attributed to the high back pressure in the vortex tube so, the tangential velocities in core and periphery would not differ substantially, duo to the lower specific volume of air, while the core axial velocities are high, this would lead to a low diffusion of kinetic energy, which also means low temperature separation. 


\subsection{Effect of the operating parameters on the vortex tube performance}

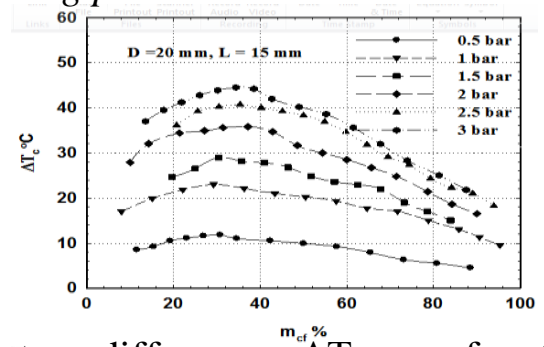

Fig. 19. Cold temperature differences $\stackrel{m_{a} \%}{\Delta T_{c}}$ as a function of cold mass fraction $\mathrm{m}_{\mathrm{cf}}$, at $\mathrm{P}_{\mathrm{i}}=3$ bar for $\mathrm{L} / \mathrm{D}=0.75$.

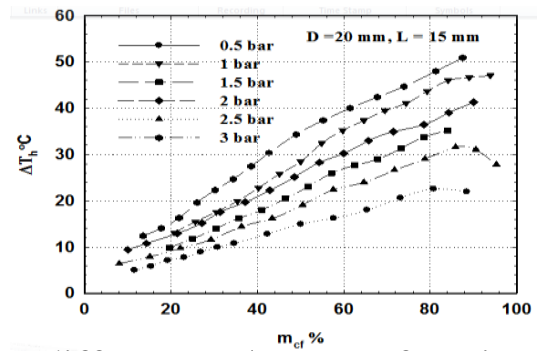

Fig. 20. Hot temperature differences $\Delta \mathrm{T}_{\mathrm{h}}^{\mathrm{m}_{\mathrm{a}} \%}$ as a function of cold mass fraction $\mathrm{m}_{\mathrm{cf}}$, at $\mathrm{P}_{\mathrm{i}}=3$ bar for $\mathrm{L} / \mathrm{D}=0.75$.

Figures- 19 and 20 show the effect of inlet pressure on the temperature differences for $\mathrm{D}=20 \mathrm{~mm}$ and $\mathrm{L}=15 \mathrm{~mm}$. inlet pressure enhance the energy separation so temperature differences increases when inlet pressure increased, but the rate of increase slows down. This situation can be explained by the chocking of the flow whatever the increasing in pressure the velocity and the mass at the outlet of the inlet nozzles don't increase.

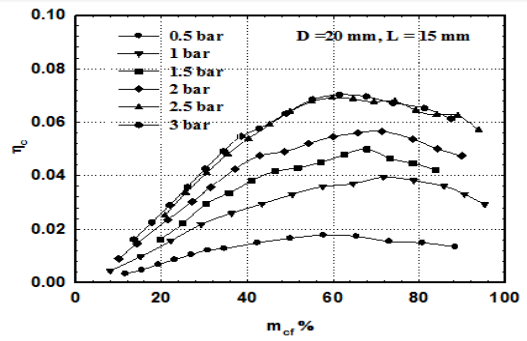

Fig. 21. Cooling efficiency $\eta_{c}$ as a function of cold mass fraction $m_{c f}$, at different $\mathrm{P}_{\mathrm{i}}$, for $\mathrm{L} / \mathrm{D}=0.75$.

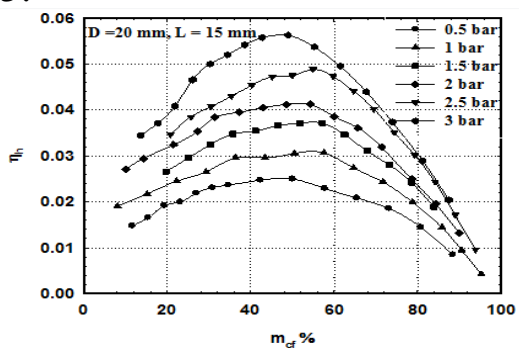

Fig. 22. Heating efficiency $\eta_{h}$ as a function of cold mass fraction $m_{c f}$, at different $\mathrm{P}_{\mathrm{i}}$, for $\mathrm{L} / \mathrm{D}=0.75$. 
From figures 21 and 22 it is seen that any increase in the inlet pressure leads to an increase in $\eta_{\mathrm{c}}$ and $\eta_{\mathrm{h}}$, but the rate of increasing decreases with the increasing at the inlet pressure as shown in figures 24-27.

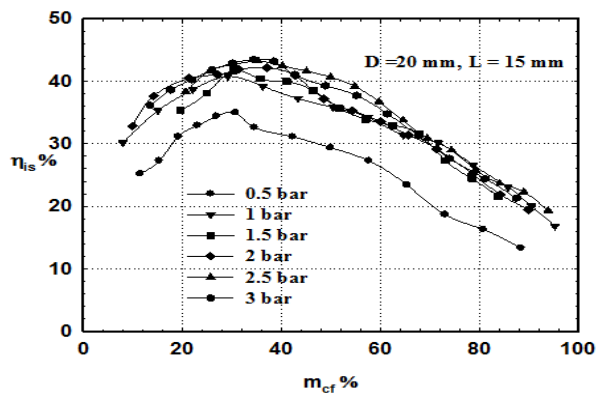

Fig. 23. Isentropic efficiency $\eta_{\text {is }}$ as a function of cold mass fraction $m_{c f}$, at different $\mathrm{Pi}$, for $\mathrm{L} / \mathrm{D}=0.75$.

Figure 23 show the effect of inlet pressure on the isentropic efficiency $\eta_{\text {is }}$ for $D=20$ $\mathrm{mm}$ and $\mathrm{L}=15 \mathrm{~mm}$. from figure 23 the highest value of $\eta_{\text {is }}$ is $43.98 \%$ at $\mathrm{m}_{\mathrm{cf}}=34.37 \%$ for $\mathrm{D}=20 \mathrm{~mm}$ and $\mathrm{L}=15 \mathrm{~mm}$ at 3 bar inlet pressure.

4.3.Effect of the geometrical parameters and inlet pressure on the cooling and heating efficiency of the vortex tube

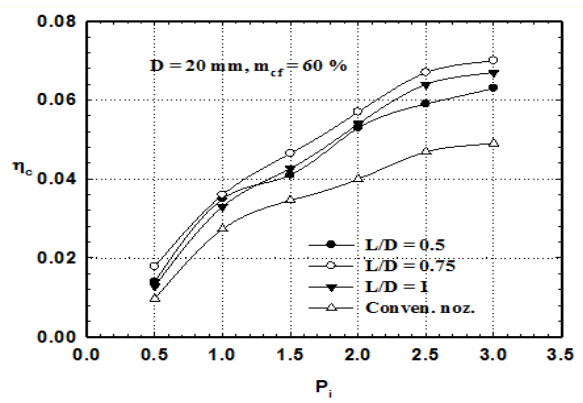

Fig. 24. Cooling efficiency $\eta_{c}$ as a function of inlet pressure $P_{i}$ at cold mass fraction $\mathrm{m}_{\mathrm{cf}}=60 \%$ and $\mathrm{D}=20 \mathrm{~mm}$, for different values of $\mathrm{L} / \mathrm{D}$.

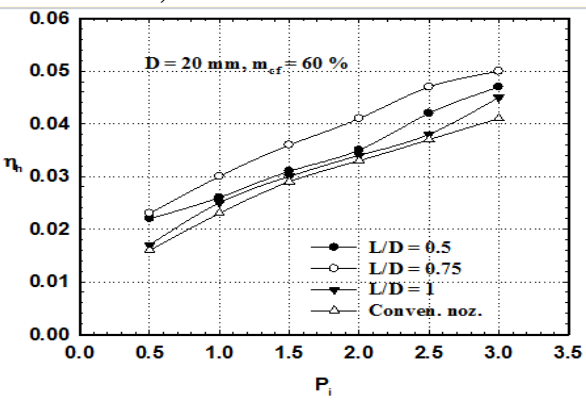

Fig. 25. Heating efficiency $\eta_{h}$ as a function of inlet pressure $P_{i}$ at cold mass fraction $\mathrm{m}_{\mathrm{cf}}=40 \%$ and $\mathrm{D}=20 \mathrm{~mm}$, for different values of $\mathrm{L} / \mathrm{D}$. 


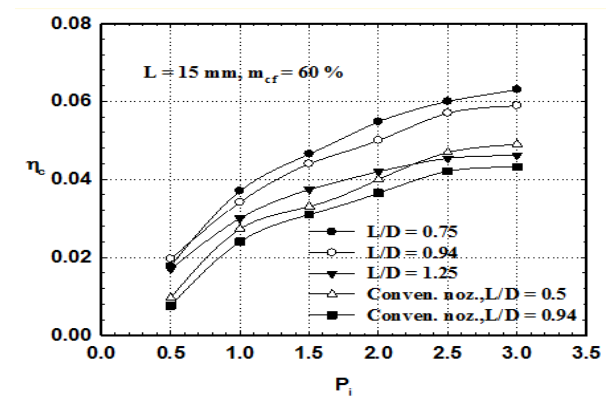

Fig. 26. Cooling efficiency $\eta_{c}$ as a function of inlet pressure $P_{i}$ at cold mass fraction $\mathrm{m}_{\mathrm{cf}}=60 \%$ and $\mathrm{L}=15 \mathrm{~mm}$, for different values of $\mathrm{L} / \mathrm{D}$.

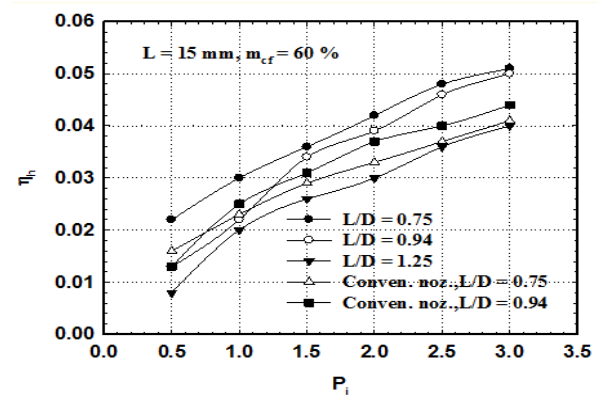

Fig. 27. Heating efficiency $\eta_{h}$ as a function of inlet pressure $P_{i}$ at cold mass fraction $\mathrm{m}_{\mathrm{cf}}=40 \%$ and $\mathrm{L}=15 \mathrm{~mm}$, for different values of $\mathrm{L} / \mathrm{D}$.

\subsection{Non dimensional parameters for vortex tube}

Figures 28-30 illustrate the variation of non-dimensional cold temperature difference, $\Delta T_{c} / T_{c, \max }$, non-dimensional refrigeration capacity, $\eta_{c} / \eta_{c, \max }$, and non-dimensional heating capacity, $\eta_{\mathrm{h}} / \eta_{\mathrm{h} \text {,max }}$ as a function of cold mass fraction, $\mathrm{m}_{\mathrm{cf}}$, for different vortex chamber geometries at different inlet pressures, respectively. It is depicted in these Figs. that the parameters $\Delta T_{c} / T_{c, \max }, \eta_{\mathrm{c}} / \eta_{\mathrm{c}, \max }$ and $\eta_{\mathrm{h}} / \eta_{\mathrm{h} \text {,max }}$ are independent of vortex chamber geometry or inlet pressurethey only depend on the cold mass fraction $\mathrm{m}_{\mathrm{cf}}$.

Empirical correlations may be introduced to the experimental data of figures $28-30$ by curve fitting as following:

$$
\begin{aligned}
& \Delta \mathrm{T}_{\mathrm{c}} / \Delta \mathrm{T}_{\mathrm{c}, \max }=3.024 \mathrm{~m}_{\mathrm{cf}}{ }^{3}-6.073 \mathrm{~m}_{\mathrm{cf}}{ }^{2}+2.993 \mathrm{~m}_{\mathrm{cf}}+0.513 \\
& \eta_{\mathrm{c}} / \eta_{\mathrm{c}, \max }=0.033 \mathrm{~m}_{\mathrm{cf}}{ }^{3}-2.733 \mathrm{~m}_{\mathrm{cf}}{ }^{2}+3.565 \mathrm{~m}_{\mathrm{cf}}-0.191 \\
& \eta_{\mathrm{h}} / \eta_{\mathrm{h}, \max }=-2.39 \mathrm{~m}_{\mathrm{cf}}{ }^{3}+0.479 \mathrm{~m}_{\mathrm{cf}}{ }^{2}+1.417 \mathrm{~m}_{\mathrm{cf}}+0.433
\end{aligned}
$$




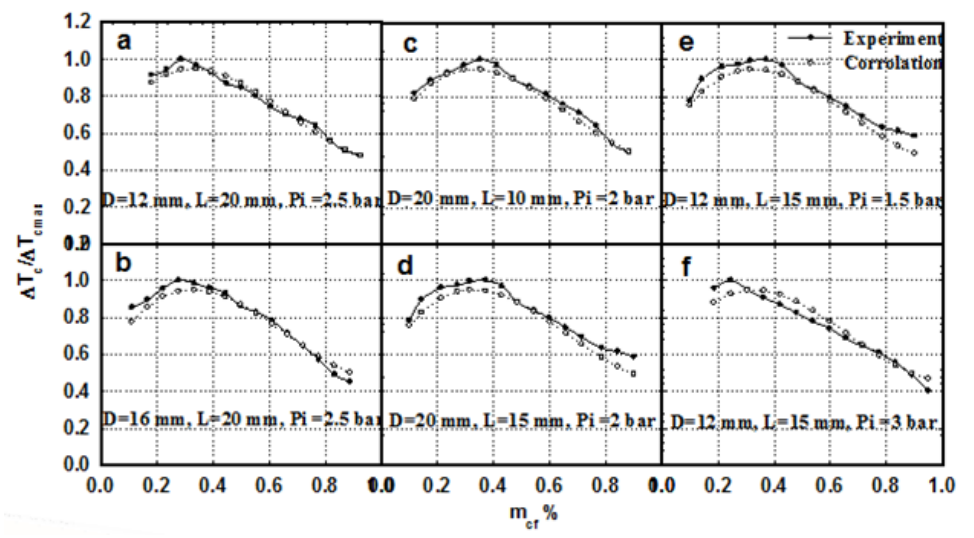

Fig. 28. Non dimensional cold temperature difference versus cold mass fraction for different vortex tube geometry at different inlet pressure.

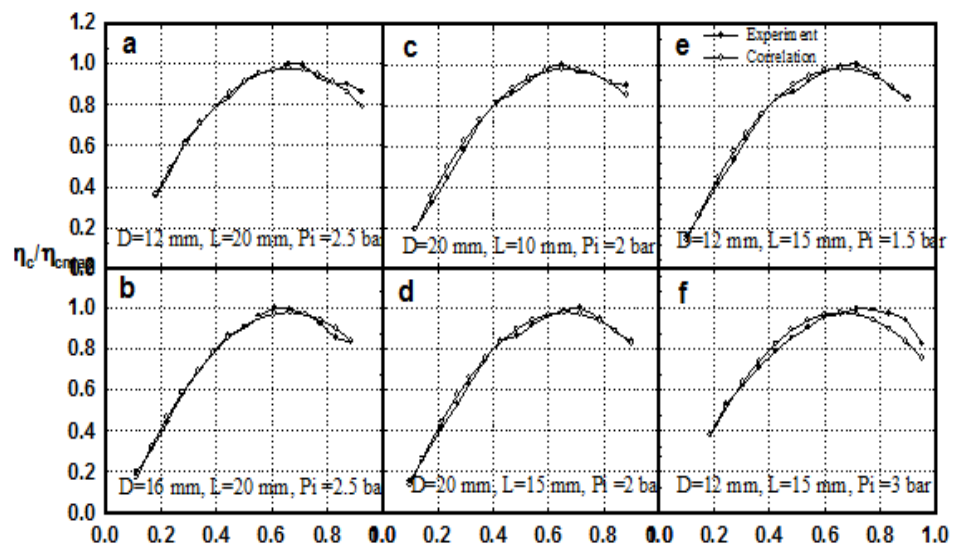

Fig. 29. Non dimensional refrigeration efficiency versus cold mass fraction for different vortex tube geometry at different inlet pressure.

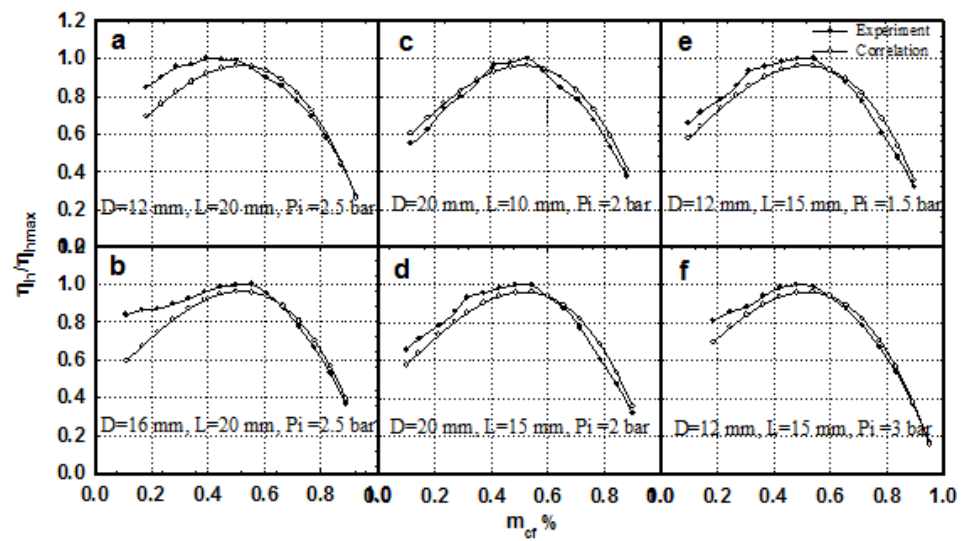

Fig. 30. Non dimensional heating efficiency versus cold mass fraction for different vortex tube geometry at different inlet pressure. 


\section{Conclusions}

An improvement in the design of the RHVT inlet is investigated. The improvement is to add a vortex chamber to the vortex tube inlet. Comparison between the new design and the conventional inlet nozzles is performed.

Variable vortex chamber lengths and diameters are investigated and tested experimentally.

The results prove that RHVT performance under all operating conditions. The vortex chamber diameter effect on RHVT performance is more pronounced than the vortex chamber length.

A vortex chamber diameter and length of 20 and $15 \mathrm{~mm}$ respectively give the best performance in case of cooling, where the cold temperature difference reaches $44.5^{\circ} \mathrm{C}$ with cold mass fraction of $34.37 \%$ at 3 bar inlet pressure.

The isentropic efficiency also enhanced with the new design, where it reaches its maximum value of $43.98 \%$ at a mass fraction of $34.37 \%$ and 3 bar inlet pressure.

A correlation equations have been deduced to demonstrate the relation of $\Delta T_{c} / T_{c, \max }$, $\eta_{\mathrm{c}} / \eta_{\mathrm{cmax}}$ and $\eta_{\mathrm{h}} / \eta_{\mathrm{hmax}}$ against $\mathrm{m}_{\mathrm{cf}}$ irrespective with vortex chamber geometries and inlet pressures.

\section{NOMENCLATURE}

D vortex chamber diameter ( $\mathrm{mm})$

d cold orifice diameter ( $\mathrm{mm}$ )

$\mathrm{L}$ vortex chamber length ( $\mathrm{mm})$

1 length ( $\mathrm{mm})$

$\mathrm{m}$ mass flow rate $\left(\mathrm{Kgs}^{-1}\right)$

$\mathrm{m}_{\mathrm{cf}}$ Cold mass fraction

$\mathrm{m}_{\mathrm{hf}}$ Hot mass fraction

$\mathrm{P}$ pressure (bar)

$\mathrm{T}$ temperature $\left({ }^{0} \mathrm{C}\right)$

$\eta_{\mathrm{c}} \quad$ Cooling efficiency

$\eta_{\mathrm{h}} \quad$ Heating efficiency

$\Delta \mathrm{T}$ Temperature difference $\left({ }^{0} \mathrm{C}\right)$

Subscripts

a ambient

c cold stream

h hot stream

i inlet

is isentropic process

$\mathrm{t}$ total

\section{Greek letters}

$\gamma \quad$ Specific heat ratio

$\eta \quad$ Efficiency $(\%)$

\begin{abstract}
Abbreviations
RHVT Ranque-Hilsch vortex tube

SLPM Standard liter per min.
\end{abstract}

\section{REFERENCES}

[1] S. Eiamsa-ard, P. Promvonge. [2008]: Review of Ranque-Hilsch effects in vortex tubes. Renewable and Sustainable Energy Reviews 12:1822-1842.

[2] Y. Xue, M. Arjomandi, R. Kelso. [2011]: A critical review of temperature separation in a vortex tube. Experimental Thermal and Fluid Science 34:1367-1374.

[3] O. Aydın, M. Baki. [2006]: An experimental study on the design parameters of a counter 
flow vortex tube. Energy 31:2763-2772.

[4] Y.T. Wu, Y. Ding, Y.B. Ji, C.F. Ma, M.C. Ge. [2007]: Modification and experimental research on vortex tube. International Journal of Refrigeration 30:1042-1049.

[5] K. Dincer, S. Baskaya, B.Z. Uysal, I. Ucgul. [2009]: Experimental investigation of the performance of a Ranque-Hilsch vortex tube with regard to a plug located at the hot outlet. International journal of refrigeration 32:87-94.

[6] O. Aydin,B. Markal, M. Avci. [2010]: A new vortex generator geometry for a counter-flow Ranque-Hilsch vortex tube. Applied Thermal Engineering 30:2505-2511.

[7] B. Markal, O. Aydın, M. Avci. [2010]: An experimental study on the effect of the valve angle of counter-flow Ranque-Hilsch vortex tubes on thermal energy separation. Experimental Thermal and Fluid Science 34:966-971.

[8] Y. Xue, M. Arjomandi. [2008]: The effect of vortex angle on the efficiency of the RanqueHilsch vortex tube. Experimental Thermal and Fluid Science 33:54-57.

[9] M.S. Valipour, N. Niazi. [2011]: Experimental modeling of a curved Ranque-Hilsch vortex tube refrigerator. International journal of refrigeration 34:1109-1116.

[10] S. Eiamsa-ard, K. Wongcharee, P. Promvonge. [2010]: Experimental investigation on energy separation in a counter-flow Ranque-Hilsch vortex tube: Effect of cooling a hot tube. International Communications in Heat and Mass Transfer 37:156-162.

[11] S. Eiamsa-ard. [2010]: Experimental investigation of energy separation in a counter-flow Ranque-Hilsch vortex tube with multiple inlet snail entries. International Communications in Heat and Mass Transfer 37:637-643.

[12] S.U. Nimbalkar, M.R. Muller. [2009]: An experimental investigation of the optimum geometry for the cold end orifice of a vortex tube. Applied Thermal Engineering 29:509514.

[13] Kun Chang, Qing Li, Gang Zhou, Qiang Li. [2011]: Experimental investigation of vortex tube refrigerator with a divergent hot tube. International journal of refrigeration 34:322327.

[14] C.M. Gao, K.J. Bosschaart, J.C.H. Zeegers, A.T.A.M. de Waele. [2005]: Experimental study on a simple Ranque-Hilsch vortex tube. Cryogenics 45:173-183.

[15] Y. Xue, M. Arjomandi, R. Kelso. [2011]: Visualization of the flow structure in a vortex tube. Experimental Thermal and Fluid Science 35:1514-1521. 


\section{دراسة الاداء لأنبوبة دوامية}

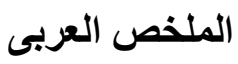

في الدر اسه الحالية تم تعديل الانبوبة الدو اميه التقليدية بتصميم جديد للغرفة الدو امية عند المدخل وتم در استها

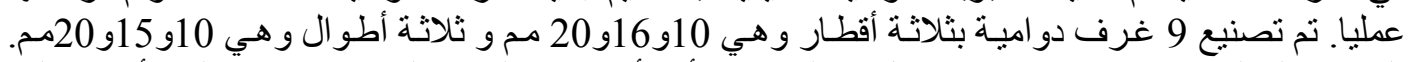

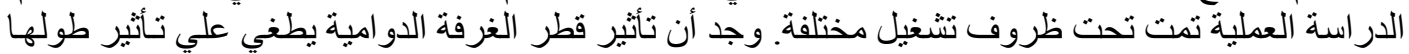

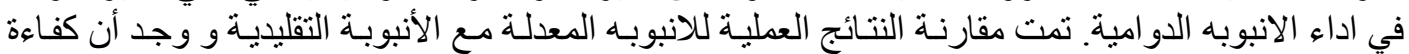
الانبوبة المعللة تحسنت عن نظيرتها التقليدية بنسبة 15.9 \% و الأنبوبة الدوائة امبة بطول 15 مم و قطر 20 مم

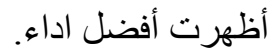

